\section{Sharing astronomical costs}

SIR-Astronomical discoveries in the past few decades have transformed our view of the Universe and what it contains. Radiation has been detected that originated in the early moments of the Universe, as well as from massive black holes, pulsing neutron stars and distant, incredibly energetic, quasistellar objects. The price of these discoveries has become increasingly high, reaching billions of dollars for the most powerful new telescopes in space.

Cooperative arrangements have been established between our countries in several areas for specific one-time-only scientific experiments and have been extremely successful. In addition, the Soviet Union and the United States have participated in ad hoc collaborations involving individual scientific groups in many different nations. In fact, in space astronomy, international experiments are now the rule rather than the exception. Ground-based astronomy could also benefit from the mutual stimulation and pooling of resources that result from such joint efforts.

We propose the establishment of an international institute for astrophysics to be organized by scientists, administrators and statesmen from the Soviet Union, the United States and from any other countries that wish to participate scientifically and financially. The joint goals of this institute would be to promote astrophysical research and to foster scientific understanding. The details of the operation and scientific programme of the institute would have to be decided on the basis of discussions among a wide range of the relevant people in the interested countries.

We mention below one exciting scientific possibility, currently beyond the ability of any one country to achieve, that serves as an example of what we have in mind. We stress that extensive discussions are required in order to choose among the large number of important projects in ground-based or in space astronomy that might become focus of the institute. The institute might begin with the long-term goal of placing a 10 -metre optical and ultraviolet telescope in space by the year 2010 , perhaps in geosynchronous or highapogee orbit. This Large Space Telescope would make possible unprecedented studies of the most distant objects in the Universe as well as revealing important new facts about our astronomical neighbours. As a first step, the institute could use available resources to place in geosynchronous orbit, with appropriate modern instrumentation, the 2.5-metre test mirror developed in connection with the Hubble Space Telescope programme. These two projects give the flavour of what is possible with such an institute.

The physical location of the institute would have to be decided by an international group that would take into account the relevant scientific and political factors. The staff would be international and the facilities would be available to all scientists of participating countries. In the first few years of its existence, the institute scientists could develop, combine and exploit the capabilities of archival research based upon existing data banks.

We call upon our colleagues and political leaders to consider the viability and desirability of this proposal.

Institute for Advanced Study, JOHN N. BAHCALL Princeton, New Jersey, USA

RICCARDO GIACCONI

Space Telescope Science Institute, Baltimore, Maryland, USA

Institute of Space MINORU ODA

and Astronautical Science,

Tokyo, Japan

Institute of Astronomy,

MARTIN REES

Cambridge, UK

ROALD SAGDEEV RASHID SUNYAEV

Space Research Institute,

Moscow, USSR

\section{CSIRO cuts}

SIR-The report of increased support for Australian science and technology (Nature 339, 167; 1989) is splendid news for Australian scientists and their colleagues overseas.

It is much less good news that in the same article it is reported that the Commonwealth and Industrial Research Organisation (CSIRO) will suffer further cuts to be added to those of recent years. These cuts arise partly from the current fashion, all too familiar in Britain, that government-supported scientific institutions should concentrate on market-orientated research and generate their own support from the private sector. This was coupled with an almost unbelievable administrative bungle, mentioned in your article, in which a large sum estimated to be coming from private industry did not materialize.

The consequences of this mismanagement are now to be inflicted on CSIRO scientists by job losses and budget cuts. These combined pressures are having disastrous effects on morale and on the work done by research groups with international reputations. For example it was astonishing to learn at a recent meeting in Southampton on marsupials as models for developmental studies, that the group led by C. H. Tyndale-Biscoe in Canberra, which has an international reputation in reproductive biology as a result of its extensive studies of one of the very few established experimental colonies of larger marsupials (tammar wallabies), is seriously considering abandoning its marsupial research to concentrate on developing new biological methods for control of rabbit and fox populations.

The explanation is that funds are not available for both the fundamental work on marsupials and the more applied studies, and that there is pressure on the group to do the latter. If marsupial studies are abandoned, the world will lose a resource and an expertise that will not easily be replaced. The Australian government should ensure that such a loss does not result from either its short-term policy on 'market-orientated research' or from bureaucratic incompetence.

NORMAN R. SAUNDERS

School of Biochemical and Physiological Sciences,

University of Southampton, Southampton SO9 3TU, UK

\section{Reprint requests}

SIR-I agree with Mathew T. MartinIverson (Nature 337, 594; 1989) and Ivor Smith (Nature 336, 708; 1988) that many scientists request reprints on the basis of the title of an article without actually reading the article. The pros and cons of requesting reprints have been discussed by the two authors. In a recent study, I sent out a questionnaire to each of the 457 individuals who requested a reprint from me to determine how and why the reprint requests were made ( $A m$. J. Dis. Children 143, 121-123; 1989). There were 259 replies available for analysis. Only 44 individuals (17 per cent) had read my article (or abstract) before the request was made. One individual ( 0.4 per cent) did not answer the question. The remaining 214 (82.6 per cent) confirmed that they had not read the article (or abstract) before the reprint request was made. The reasons for requesting reprints were: journal not available locally (156 responses), photocopying facilities not available locally (8), photocopying prohibited by copyright regulations (7), high quality of the reprint $(95)$, local institution would pay for the mailing of the reprint cards or letters but not for the photocopying (14), library not readily accessible (8), photocopying time-consuming (8), personal contact with the author (1) and spacesaving for reprint libraries (8).

It must be remembered that reprints are costly to authors and reprints should not be requested unless there is a really good reason for it.

Alexander K. C. Leung

Department of Pediatrics,

University of Calgary,

Alberta Children's Hospital,

Calgary, Alberta,

Canada T2T $5 C 7$ 